is that its study was almost entirely confined to Buddhist circles, both in India and China.

A further statement made by Prof. Lippmann, to the effect that Stapleton, Husain, and Azo support an Arabic origin of Chinese alchemy, is incorrect, as will be seen by referring to the publication of these authors, or to my summary of it. ${ }^{5}$ A similar inversion of the views of these authors appears in Prof. Lippmann's account of Indian alchemy, ${ }^{6}$ and many such examples of lack of care in quoting authorities could be given from both his volumes. That an unfamiliarity with a foreign language might be the cause does not seem to be a satisfactory explanation, since the same course is taken with publications in German (see, for example, the reference to Hammer-Jensen's work on p. 9, and the very serious error with respect to Roger Bacon on p. 53, ref. 2 ).

The difficulty about quoting 'authorities' in the way adopted by Prof. Lippmann is that almost any view may be supported by a suitable choice of authority. An example in my own experience may serve to illustrate this, since an eminent authority on China referred me to a recent paper on Chinese alchemy in which it was asserted that alchemy began in China in 1100 B.C., that the Chinese had a theory of phlogiston several centuries before Becher and Stahl, and that glass was made in China in prehistoric times. Most of the publications on Chinese alchemy merely repeat what was collected by Edkins; although Wieger's great treatise on Taoism ${ }^{7}$ gives a list of more than a hundred and fifty Chinese treatises on alchemy, not one of these has been critically examined or translated. A beginning in this study, the necessity of which was pointed out in my original notes, ${ }^{1}$ has been made by Prof. T. L. Davis with the assistance of a native scholar, and since he has been fortunate enough to enlist sympathy in a region where I personally found none, we may expect some real additions to knowledge. The purpose of this note is mainly to indicate the doubtful value of a source of information which may be quoted as authoritative, and to the necessity of preserving a perfectly open mind on the question. J. R. Partington.

81 Barn Hill,

Wembley, Middlesex.

1 NATURe, 119, 11; 1927: see also ibid., 120, 158, 878; 1928-which are not mentioned by Lippmann.

Isis, 12, 330; 1929 .

" "La Chine antique", Paris, 1927.

: Berthelot, "Chimie au moyen âge", vol. 3, p. 40

Nature, 120, 158, 242; 1927.

A Alchemie, 2, 23.

7 Vol. 1,1911 .

\section{New Yields from the Oldoway Bone Beds, Tanganyika Territory.}

In NATURE for Oct. 24, 1931, a letter from us was published giving the first results of our work at Oldoway in Tanganyika Territory ; we should be grateful if the following additional results could be recorded :

(1) Bed No. 1, the lowest bed in the Oldoway series, has now yielded an extensive fauna which includes Deinotherium sp., Hipparion sp., and also Elephas (antiqus recki?). The Deinotherium cannot be regarded as a derived fossil, since five complete teeth were found amongst a partially articulated skele. ton. In Bed 1, at two different sites, we have found artefacts of a Pre-Chellean type actually with Deinotherium.

(2) Bed No. 2, at its base, contains tools of an early Chellean type of large size, and in its upper part, at the same horizon as the human skeleton found by Reck in 1913, tools of a more advanced Chellean type. Thus Homo sapiens is shown to be the contemporary, and presumably the maker, of an advanced Chellean type of culture. The fauna includes Hipparion and Elephas antiqus recki.

(3) Bed No. 3 has yielded a series of tools which may be regarded as transitional from the Chellean to the Acheulean stage of culture development.

(4) Bed No. 4, in its lower part, has yielded a big series of tools of an early Acheulean type, whilst in its higher levels we have found an old open station site which has yielded more than 500 perfect advanced Acheulean type tools. Even Bed No. 4 includes in its fauna Elephas antiqus recki, Hipparion, Pelorovis, Hippopotamus gorgops, and Equus sp., and we know, from the results of the material obtained by Reck in 1913 , that more than fifty per cent of the species are extinct.

(5) Bed No. 5 overlies the other four beds unconformably and is separated from them by a long period of earth movement and erosion. At two sites in bed No. 5 we have found tools of an upper Kenya Aurignacian type.

(6) In view of the evidence of the fauna, and also in view of the fact that we have in beds Nos. 1 to 4 the gradual evolution from a Pre-Chellean type of culture to a developed Acheulean, we incline to the view that this part of the Oldoway series represents the lower and middle Pleistocene, a period which Leakey and Solomon have shown to be represented in Kenya by Gregory's Kamasian series.

L. S. B. LEAKEY.

Arthur T. Hopwood.

Hans Reck.

East African Archæological Expedition, Nov. 30, 1931.

Latency of Seedlings in some Grasses.

ExPERIMENTs at this Station have shown that when seeds of Lolium italicum are sown in the field together with those of certain other grasses (notably Festuca pratensis, Phleum pratense, and Poa trivialis), the early establishment of the latter may be considerably diminished as compared with that occurring in the absence of the rye-grass. Some months after sowing, an increase in the establishment of the same grasses is often shown. In seeking an explanation of this behaviour, a peculiar property of grass seedlings has been revealed.

Under certain conditions, when seeds of $F$. pratensis, $P$. pratense, and $P$. trivialis are sown between plants of $L$. italicum, the seedlings which result develop with extreme slowness, and after several months are no larger in size than is normally the case two weeks after germination. Such seedlings, growing in the open under conditions of low mineral nutrition and poor illumination, have been found to be remarkably persistent. The mortality in seedlings of $F$. pratensis has been after 10 months 29 per cent; in seedlings of $P$. pratense, 3 per cent after 4 months; and in those of $P$.trivialis, 4 per cent after 3 months; a high proportion of the seedlings of each species has remained alive for much longer periods.

In each case, the seedlings proved capable of normal. development when transferred to a favourable environment.

There is no reason to suppose that this behaviour is peculiar to these species only of grasses, and its importance to agricultural practice is obvious. It would also seem probable that the ability of seedlings to persist for long periods in an environment unfavourable to growth and to develop normally after. wards must be an important factor in competition under feral conditions. In the colonisation of denuded areas, for example, its effect would be to increase the 